Reply

\title{
Reply to Auclin et al. Comment on "Hopkins et al. Value of the Lung Immune Prognostic Index in Patients with Non-Small Cell Lung Cancer Initiating First-Line Atezolizumab Combination Therapy: Subgroup Analysis of the IMPOWER150 Trial. Cancers 2021, 13, 1176"
}

\author{
Ashley M. Hopkins $\left.{ }^{1, *} \mathbb{(}\right)$, Ganessan Kichenadasse ${ }^{1,2} \oplus$, Ahmad Y. Abuhelwa ${ }^{1} \oplus$, Ross A. McKinnon ${ }^{1}$, \\ Andrew Rowland ${ }^{1}$ and Michael J. Sorich ${ }^{1}$ (iD \\ 1 College of Medicine and Public Health, Flinders University, Bedford Park, SA 5042, Australia; \\ ganessan.kichenadasse@flinders.edu.au (G.K.); ahmad.abuhelwa@flinders.edu.au (A.Y.A.); \\ ross.mckinnon@flinders.edu.au (R.A.M.); andrew.rowland@flinders.edu.au (A.R.); \\ michael.sorich@flinders.edu.au (M.J.S.) \\ 2 Department of Medical Oncology, Flinders Medical Centre, Adelaide, SA 5042, Australia \\ check for \\ updates
}

Citation: Hopkins, A.M.;

Kichenadasse, G.; Abuhelwa, A.Y.; McKinnon, R.A.; Rowland, A.; Sorich, M.J. Reply to Auclin et al. Comment on "Hopkins et al. Value of the Lung Immune Prognostic Index in Patients with Non-Small Cell Lung Cancer Initiating First-Line Atezolizumab Combination Therapy: Subgroup Analysis of the IMPOWER150 Trial. Cancers 2021, 13, 1176". Cancers 2021, 13, 3763. https://doi.org/10.3390/ cancers13153763

Academic Editor: Lucia

Mincheva-Nilsson

Received: 11 June 2021

Accepted: 22 July 2021

Published: 27 July 2021

Publisher's Note: MDPI stays neutral with regard to jurisdictional claims in published maps and institutional affiliations.

Copyright: (c) 2021 by the authors. Licensee MDPI, Basel, Switzerland. This article is an open access article distributed under the terms and conditions of the Creative Commons Attribution (CC BY) license (https:// creativecommons.org/licenses/by/ $4.0 /)$.
We thank Auclin et al. [1] for the comments on our manuscript in Cancers titled "Value of the Lung Immune Prognostic Index (LIPI) in Patients with Non-Small Cell Lung Cancer (NSCLC) Initiating First-Line Atezolizumab Combination Therapy: Subgroup Analysis of the IMpower150 Trial" [2]. We read with interest the elements of the approach proposed by Auclin et al.'s [1] to integrate LIPI into routine clinical practice and, specifically: (1) to validate LIPI retrospectively in previous clinical trials with immunotherapy; (2) to design prospective clinical trials including LIPI as a stratification factor; and (3) to design prospective clinical trials using LIPI as a marker for guiding treatment selection. However, caution is required to ensure the development of 'host-related inflammatory indices' for immunotherapies are well planned and target the key factors enabling precision immunotherapy use in oncology.

Auclin et al. [1] provide valid comment that LIPI needs to continue to be investigated in post hoc analysis of clinical trials involving immunotherapies. It is well appreciated that single clinical trials are usually underpowered to statistically evaluate differences in treatment effect between arms across baseline subgroups [3]. Thus, it is not surprising that in our analysis of IMpower150 the change in relative overall survival treatment effect of atezolizumab-bevacizumab-carboplatin-paclitaxel (ABCP) versus bevacizumabcarboplatin-paclitaxel (BCP) (and $\mathrm{ACP}$ vs. $\mathrm{BCP}$ ) did not show any statistical difference across the LIPI subgroups (P-interaction $=0.66)$, despite no absolute benefit in median overall survival being observed in the poor LIPI group [2]. Reiterating, research needs: (1) to pool trials to increase the power to conclusively determine treatment effects within the poor LIPI group; (2) to evaluate LIPI performance for other immune checkpoint inhibitor combination approaches; and (3) to evaluate LIPI prognostic performance within a large real-world cohort. Auclin et al. [1] also highlight EGFR/ALK and immunotherapy crossover populations are subgroups of interest for further investigation, which were beyond the scope of our analysis in a single trial.

Based on current and emerging data [1,2,4-6] there is validity in the recommendation that prospective investigations of immunotherapies should consider inclusion of LIPI as a stratification factor in trial design. At a minimum, immunotherapy trial publications need to report the distributions of inflammatory markers (e.g., neutrophil to lymphocyte ratio, lactate dehydrogenase, c-reactive protein) to enable assessment of randomization validity and potential introduction of bias to trial findings [7]. 
With respect to LIPI guiding treatment selection in planned prospective clinical trials, careful consideration of the key clinical potentials of the inflammatory indices are required. As requested, Figure 1 provides Kaplan-Meier estimates of overall survival and progression-free survival according to LIPI groups for patients treated with BCP in IMpower150 [2]. Within the 381 evaluable participants randomised to $\mathrm{BCP}$, median OS ranged from 9 months for the poor LIPI group to 23 months for the good LIPI group $(p<0.001)$ [2]. LIPI OS discrimination performance (c-statistic) was 0.67 in the BCP cohort, compared to 0.63 and 0.63 in the $\mathrm{ABCP}$ and $\mathrm{ACP}$ cohorts, respectively [2]. Such data presents LIPI is not immunotherapy specific, and that limiting immunotherapy access in clinical trials is premature. Rather, we propose that LIPI is worthy of consideration for regulators as a baseline read-out for pay for performance strategies and as an easy-to-use clinical tool for both shared decision making and setting realistic expectations of likely outcomes to immunotherapies. We also encourage the comparison of LIPI to other emerging predictor tools [7] and the incorporation of clinicopathological makers (e.g., c-reactive protein, body mass index, or concomitant medicines) which may potentiate the immunotherapy specificity of the LIPI metric [7-11].
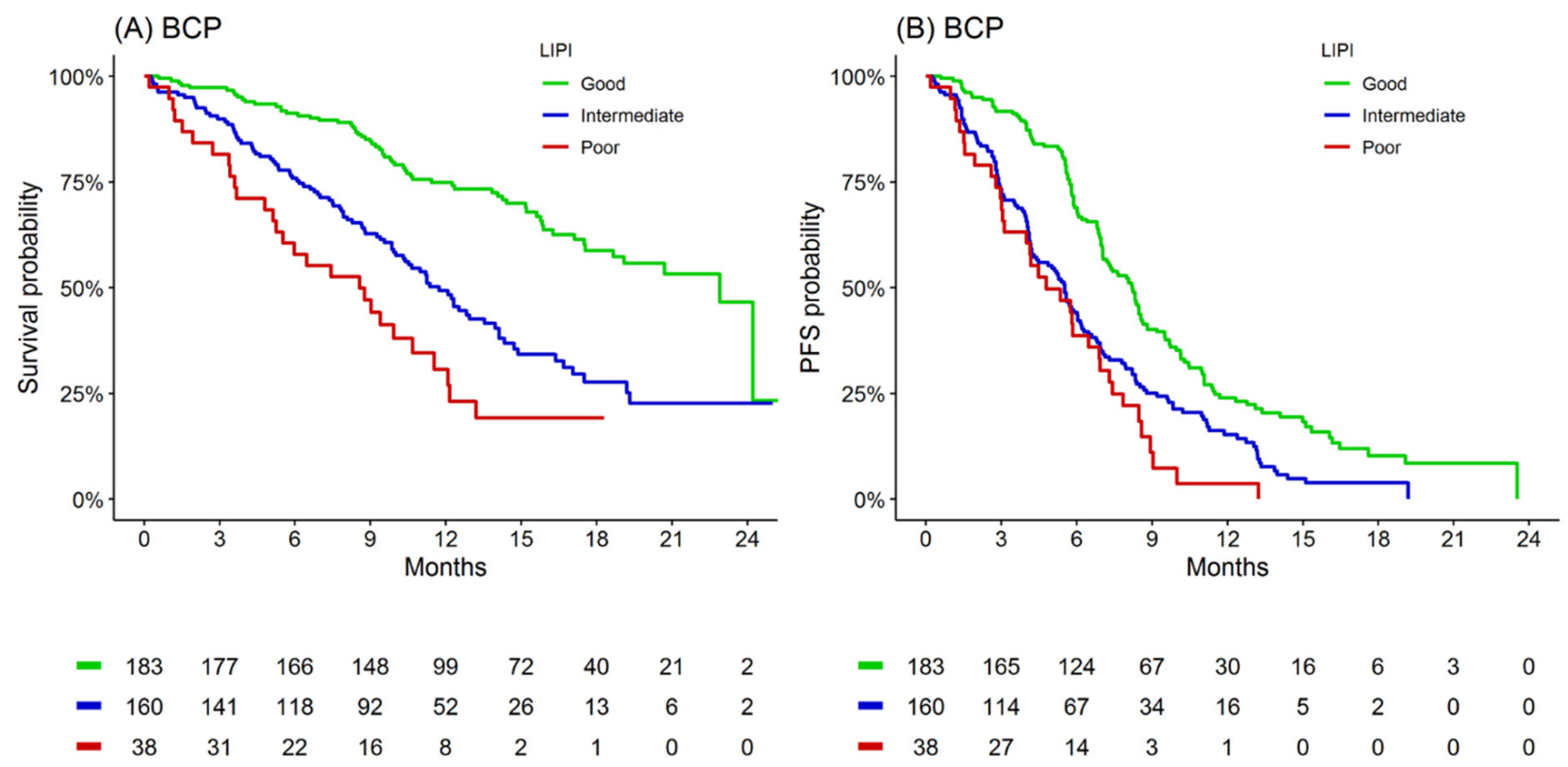

Figure 1. Kaplan-Meier estimates of overall survival and progression-free survival according to LIPI group for patients treated with BCP. (A) Overall survival and (B) progression-free survival.

In conclusion, LIPI is a significant prognostic marker of overall survival and progressionfree survival in patients with chemotherapy-naïve, metastatic non-squamous NSCLC who initiate any of $\mathrm{ABCP}, \mathrm{ACP}$, or $\mathrm{BCP}$ therapy. With respect to treatment benefit, the study provides additional evidence that within the poor LIPI group immunotherapies are associated with reduced overall survival and progression-free survival benefit. This highlights the importance of future investigations of the clinical potential of immunotherapy prediction models to support shared decision making, provide realistic expectations to treatment, and inform regulators of cost-effectiveness across subgroups (i.e., small enhancements in prediction performance compared to LIPI have significant potential for major clinical impacts).

Author Contributions: Conception and design A.M.H. and M.J.S.; development of methodology A.M.H., A.R. and M.J.S.; acquisition of data (provided animals, acquired and managed patients, provided facilities, etc.) A.M.H., A.Y.A., A.R. and M.J.S.; analysis and interpretation of data (e.g., statistical analysis, biostatistics, computational analysis) A.M.H., G.K., A.Y.A., R.A.M., A.R. and M.J.S.; writing, review, and/or revision of the manuscript A.M.H., G.K., A.Y.A., R.A.M., A.R. and 
M.J.S.; administrative, technical, or material support (i.e., reporting or organizing data, constructing databases) A.M.H., R.A.M., A.R. and M.J.S.; study supervision A.M.H., R.A.M., A.R. and M.J.S. All authors have read and agreed to the published version of the manuscript.

Funding: R.A.M., A.R. and M.J.S. are supported by Beat Cancer Research Fellowships from Cancer Council South Australia. A.M.H. is supported by a Postdoctoral Fellowship from the National Breast Cancer Foundation, Australia (PF-17-007). Data access and salary of A.Y.A. was supported by funding from an Australian, Tour de Cure Early Career Research Grant (RSP-155-18/19).

Institutional Review Board Statement: Secondary analysis of anonymized clinical trial data was confirmed negligible risk research by the Southern Adelaide Local Health Network, Office for Research and Ethics and was exempt from review.

Informed Consent Statement: Not applicable to this independent secondary analysis study.

Data Availability Statement: Data and results for this comment were extracted from publication Hopkins et al. Value of the Lung Immune Prognostic Index in Patients with Non-Small Cell Lung Cancer Initiating First-Line Atezolizumab Combination Therapy: Subgroup Analysis of the IMpower150 Trial. Cancers, 2021, 13(5), 1176.

Conflicts of Interest: R.A.M., A.R. and M.J.S. report investigator-initiated project grants from Pfizer, outside the submitted work. G.K., A.Y.A. and A.M.H. have no conflicts of interest to disclose. The funders had no role in the design and conduct of the study; collection, management, analysis, and interpretation of the data; preparation, review, or approval of the manuscript; and decision to submit. This publication is based on research using data from Roche that has been made available through Vivli, Inc. Vivli has not contributed to or approved, and is not in any way responsible for the contents of, this publication. The funders had no role in the design and conduct of the study; collection, management, analysis, and interpretation of the data; preparation, review, or approval of the manuscript; and decision to submit.

\section{References}

1. Auclin, E.; Mezquita, L.; Besse, B. Comment on Hopkins et al. Value of the Lung Immune Prognostic Index in Patients with Non-Small Cell Lung Cancer Initiating First-Line Atezolizumab Combination Therapy: Subgroup Analysis of the IMPOWER150 Trial. Cancers 2021, 13, 1176. Cancers 2021, 13, 3624. [CrossRef]

2. Hopkins, A.M.; Kichenadasse, G.; Abuhelwa, A.Y.; McKinnon, R.A.; Rowland, A.; Sorich, M.J. Value of the Lung Immune Prognostic Index in Patients with Non-Small Cell Lung Cancer Initiating First-Line Atezolizumab Combination Therapy: Subgroup Analysis of the IMPOWER150 Trial. Cancers 2021, 13, 1176. [CrossRef] [PubMed]

3. Wang, R.; Lagakos, S.W.; Ware, J.H.; Hunter, D.J.; Drazen, J.M. Statistics in Medicine-Reporting of Subgroup Analyses in Clinical Trials. N. Engl. J. Med. 2007, 357, 2189-2194. [CrossRef] [PubMed]

4. Sorich, M.J.; Rowland, A.; Karapetis, C.S.; Hopkins, A.M. Evaluation of the Lung Immune Prognostic Index for Prediction of Survival and Response in Patients Treated With Atezolizumab for NSCLC: Pooled Analysis of Clinical Trials. J. Thorac. Oncol. Off. Publ. Int. Assoc. Study Lung Cancer 2019, 14, 1440-1446. [CrossRef] [PubMed]

5. Mezquita, L.; Auclin, E.; Ferrara, R.; Charrier, M.; Remon, J.; Planchard, D.; Ponce, S.; Ares, L.P.; Leroy, L.; Audigier-Valette, C.; et al. Association of the Lung Immune Prognostic Index With Immune Checkpoint Inhibitor Outcomes in Patients With Advanced Non-Small Cell Lung Cancer. JAMA Oncol. 2018, 4, 351-357. [CrossRef] [PubMed]

6. Kazandjian, D.; Gong, Y.; Keegan, P.; Pazdur, R.; Blumenthal, G.M. Prognostic Value of the Lung Immune Prognostic Index for Patients Treated for Metastatic Non-Small Cell Lung Cancer. JAMA Oncol. 2019, 5, 1481-1485. [CrossRef]

7. Hopkins, A.M.; Kichenadasse, G.; Garrett-Mayer, E.; Karapetis, C.S.; Rowland, A.; Sorich, M.J. Development and Validation of a Prognostic Model for Patients with Advanced Lung Cancer Treated with the Immune Checkpoint Inhibitor Atezolizumab. Clin. Cancer Res. Off. J. Am. Assoc. Cancer Res. 2020, 26, 3280-3286. [CrossRef]

8. Abuhelwa, A.Y.; Kichenadasse, G.; McKinnon, R.A.; Rowland, A.; Hopkins, A.M.; Sorich, M.J. Machine Learning for Prediction of Survival Outcomes with Immune-Checkpoint Inhibitors in Urothelial Cancer. Cancers 2021, 13, 2001. [CrossRef] [PubMed]

9. Kichenadasse, G.; Miners, J.O.; Mangoni, A.A.; Rowland, A.; Hopkins, A.M.; Sorich, M.J. Association Between Body Mass Index and Overall Survival With Immune Checkpoint Inhibitor Therapy for Advanced Non-Small Cell Lung Cancer. JAMA Oncol. 2020, 6, 512-518. [CrossRef] [PubMed]

10. Hopkins, A.M.; Kichenadasse, G.; Karapetis, C.S.; Rowland, A.; Sorich, M.J. Concomitant Proton Pump Inhibitor Use and Survival in Urothelial Carcinoma Treated with Atezolizumab. Clin. Cancer Res. 2020, 26, 5487-5493. [CrossRef] [PubMed]

11. Hopkins, A.M.; Kichenadasse, G.; Karapetis, C.S.; Rowland, A.; Sorich, M.J. Concomitant Antibiotic Use and Survival in Urothelial Carcinoma Treated with Atezolizumab. Eur. Urol. 2020, 78, 540-543. [CrossRef] [PubMed] 